\title{
ИССЛЕДОВАНИЕ ПОДХОДОВ ДЛЯ СОЗДАНИЯ ГЕОКОГНИТИВНЫХ КАРТ ЦЕНОВОГО ЗОНИРОВАНИЯ ОБЪЕКТОВ НЕДВИЖИМОСТИ
}

\section{Евгений Сергеевич Антонов}

Новосибирское Высшее командное училище, 630117, Россия, г. Новосибирск, ул. Иванова, 49, начальник лаборатории кафедры тактики, тел. (383) 332-50-45, e-mail: Nvvku2007@mail.ru

\section{Алексей Викторович Дубровский}

Сибирский государственный университет геосистем и технологий, 630108, Россия, г. Новосибирск, ул. Плахотного, 10, кандидат технических наук, заведующий кафедрой кадастра и территориального планирования, тел. (383)361-01-09, e-mail: avd5@ssga.ru

\section{Нина Алексеевна Беляева}

Сибирский государственный университет геосистем и технологий, 630108, Россия, г. Новосибирск, ул. Плахотного, 10, обучающийся, тел. (383)361-01-09, e-mail: nin-bel1998@mail.ru

В статье показаны задачи, которые можно решить с использованием карт ценового зонирования территории населенных пунктов. Главными задачами являются информационное обеспечение планирования развития пространства города, а также повышение уровня комфортности социально-бытовой инфраструктуры. Предлагается в качестве инструмента картографической визуализации данных о стоимости недвижимости использовать подходы для создания геокогнитивных карт. В статье дано описание пяти предлагаемых авторами способов по созданию цифровых картографических произведений с элементами когнитивного представления информации. Для каждого способа представлен пример оформления геокогнитивной карты ценового зонирования. В заключении сделаны выводы о перспективности применения геокогнитивных карт в современном кадастре и территориальном управлении.

Ключевые слова: ценовое зонирование, когнитивные карты, геоинформационные системы, цифровая картография, объекты недвижимости

\section{RESEARCH OF APPROACHES FOR CREATING COGNITIVE MAPS OF REAL ESTATE PRICE ZONING}

\section{Evgeny S. Antonov}

Novosibirsk Higher Command School, 49, Ivanova St., Novosibirsk, 630117, Russia, Head of the Laboratory of the Department of Tactics, phone: (383)332-50-45, e-mail: Nvvku2007@mail.ru

\section{Alexey V. Dubrovsky}

Siberian State University of Geosystems and Technologies, 10, Plakhotnogo St., Novosibirsk, 630108, Russia, Ph. D., Head of the Department of Cadastre and Territorial Planning, phone: (383)361-01-09, e-mail: avd5@ssga.ru

\section{Nina A. Belyaeva}

Siberian State University of Geosystems and Technologies, 10, Plakhotnogo St., Novosibirsk, 630108, Russia, Student, phone: (383)361-01-09, e-mail: nin-bel1998@mail.ru

The article deals with the problems solved with the use of maps of price zoning of the territory of localities. The main tasks are information support for planning the development of the city and improving the level of comfort of social and household infrastructure. To create price zoning maps, 
we suggest using cognitive maps. The article describes five ways to create digital maps with elements of cognitive representation of information. For each method, an example of the design of a cognitive map of price zoning is presented. In conclusion, conclusions are drawn about the prospects of using cognitive maps in modern cadastre and territorial administration.

Keywords: price zoning, cognitive maps, geographic information systems, digital cartography, real estate

Ценовое зонирование объектов недвижимости на территории населенных пунктов выполняется для решения следующих задач [1]:

- информационное обеспечение государственной кадастровой оценки;

- привлечение инвестиций в развитие территории;

- анализ стоимости недвижимости в зависимости от ее местоположения для разработки стратегии социально-экономического развития и ликвидации дисбаланса между различными участками на территории города;

- определение рейтинга города по стоимостным показателям недвижимости среди других городов страны;

- информационно-рекламное обеспечение рынка недвижимости.

Решение перечисленных задач существенно расширяет возможности разработки продуманной управленческой политики для целей территориального развития городского пространства. При этом главной целью является создание равноценного уровня социально-бытовой инфраструктуры на территории населенного пункта [2].

Основными элементами системы ценового зонирования объектов недвижимости являются [3]:

- статистические данные о стоимости объектов недвижимости;

- алгоритмы усреднения показателей стоимости и выбора шага изменения оценочных зон;

- методы и приемы картографической визуализации информации по стоимости объектов недвижимости и ценовым зонам.

В некоторых случаях в модель ценового зонирования включаются данные, которые влияют на изменение стоимости недвижимости. Например, это могут быть данные о проектируемых остановках общественного транспорта, станций метро, объектах социально-бытовой инфраструктуры, уличнодорожной сети и т.п.

При анализе изменения стоимости объектов недвижимости выполняется прогнозная аппроксимация стоимости объектов аналогов. Например, строительство и ввод в эксплуатацию новой школы увеличивает стоимость жилой недвижимости в соседних дворах на 10-15\%, детского садика на 5-8\%. Одним из примеров влияния объектов социальной инфраструктуры на стоимость недвижимости является прогнозное моделирование роста стоимости недвижимости в городе Новосибирске в результате строительства Ледовой Арены, рис. 1 $[4,5]$. 


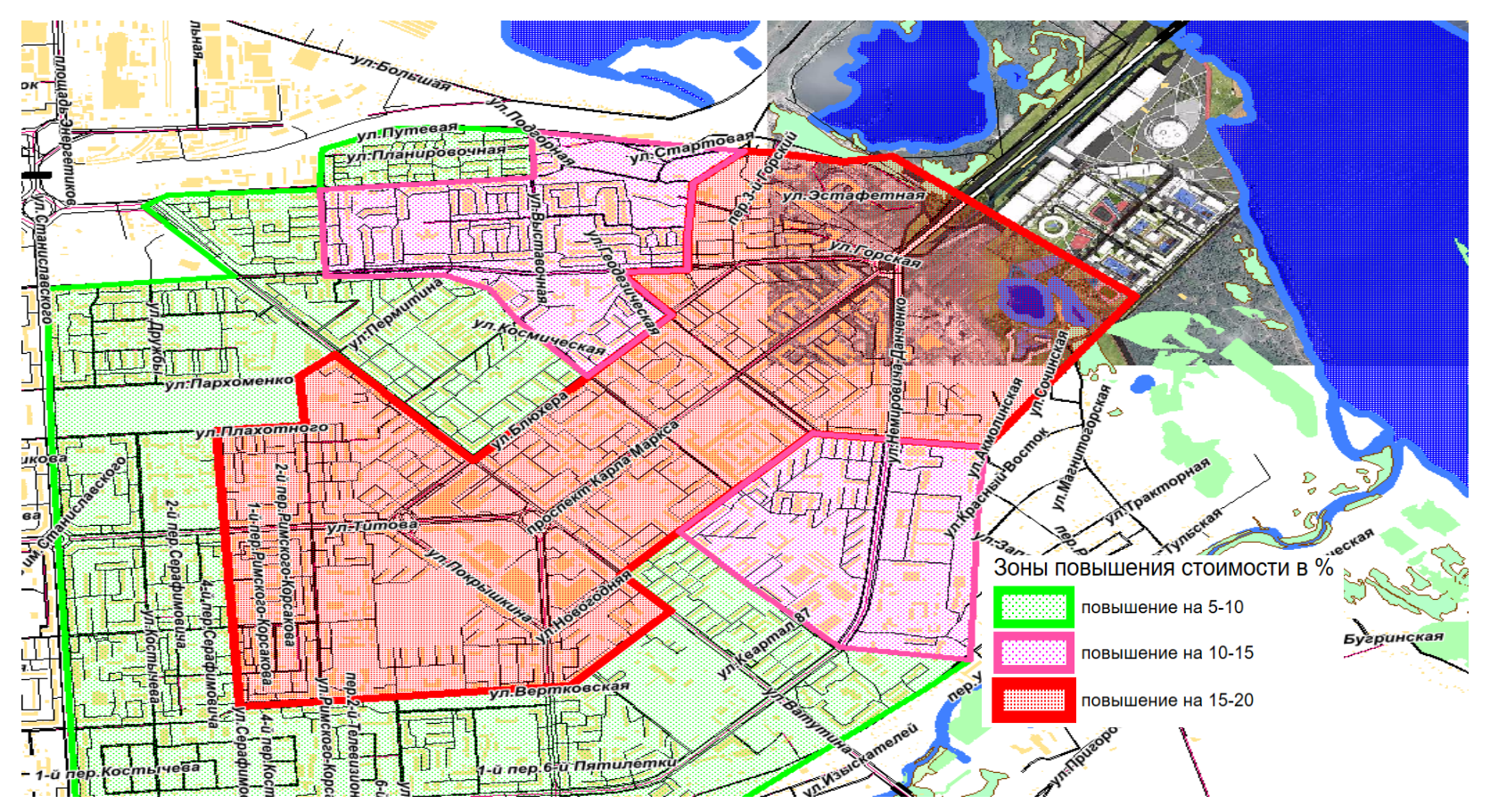

Рис. 1. Прогнозное моделирование роста стоимости недвижимости в городе Новосибирске в результате строительства Ледовой Арены

Таким образом, для визуализации результатов ценового зонирования территории по значению стоимости объектов недвижимости наиболее информативно, удобно и рационально применять способы картографической визуализации $[6,7]$. При этом формируется картографическое произведение, которое в силу специфических свойств своего содержания обладает когнитивностью способностью восприниматься человеком, как объект познания, поддающийся умственной переработке информационного наполнения. В результате происходит формирование комплексного представления об объекте картографирования. То есть карты ценового зонирования представляю собой один из видов тематических карт и визуализируют образы пространственных объектов, процессов и явлений в понятных концепциях, формах, символах, цветовых характеристиках, несущих информационную нагрузку, которая может быть обработана человеком для получения нового знания.

Термин «когнитивная карта» как образа знакомого пространственного окружения был предложен американским ученым Э. Ч. Толменом в середине прошлого века. Такие карты не могут претендовать на географическую точность и абсолютное соответствие пространственным параметрам этого мира [8].

В настоящее время наступила потребность в отображении геопространственных знаний (геознаний) о территориях. Визуальной формой представления геознаний служит новый вид карт - геокогнитивные карты. Геокогнитивная карта является не только визуальной формой представления геознаний, но и аналитической, логичной репрезентацией геоинформации, направленной на 
производство нового знания. Гекогнитивная карта дает возможность анализировать, структурировать и представлять в удобной форме любую актуальную информацию, а также преобразовывать, совершенствовать и применять на практике полученный интеллектуальный продукт [9].

Для картографической визуализации ценовых зон предлагается рассмотреть следующие способы геокогнитивной передачи информации по стоимости недвижимости [2, 6, 7, 10-12]:

- использование градиентной заливки. Этот способ удобен для отображения разных значений стоимости объектов недвижимости. Подобный прием визуализации особенно нагляден при создании разновременной когнитивной карты, отображающей динамику изменения стоимости недвижимости. На рис. 2 показаны примеры разновременных карт ценового зонирования недвижимости на территории города Новосибирска в 2016, 2017 и 2018 годах;
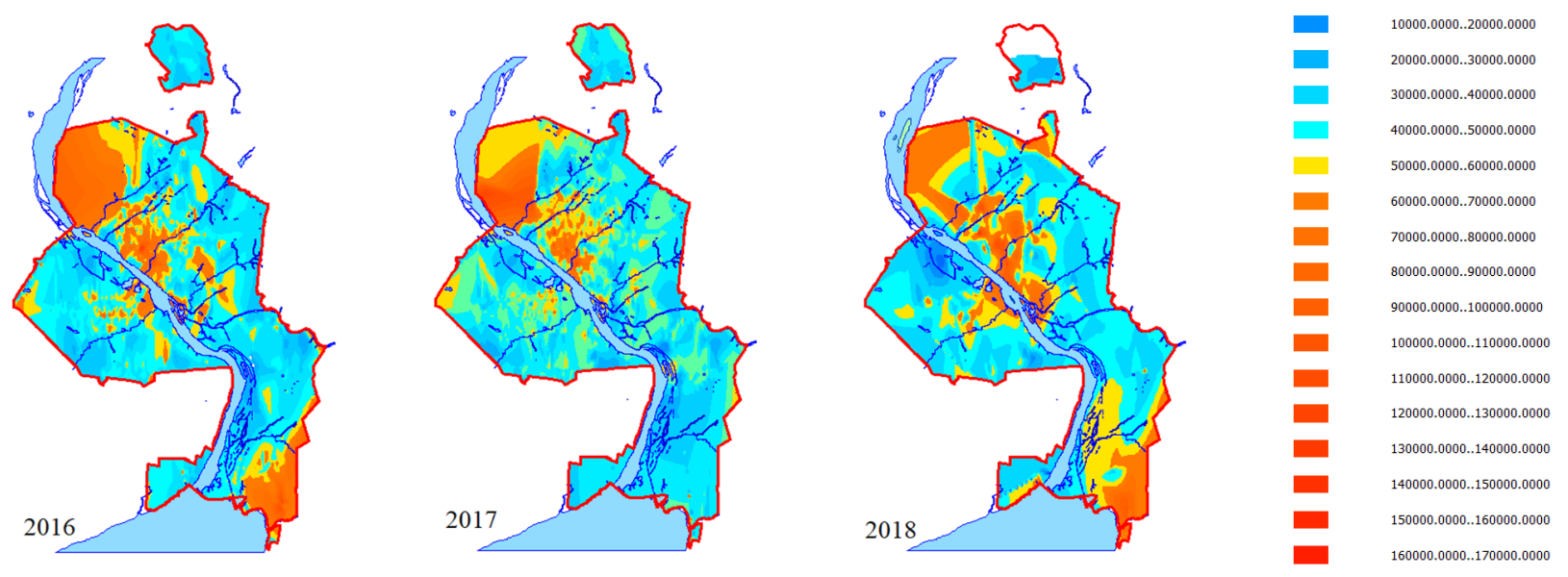

Рис. 2. Разновременные карты ценового зонирования недвижимости на территории города Новосибирска в 2016, 2017 и 2018 годах

- буквенно-цифровое обозначение картографируемых параметров. Этот способ является наиболее простым, однако в сочетании со способом градиентной заливки он является высоко информативным и удобным для выполнения анализа и последующей интерпретации данных, рис. 3;

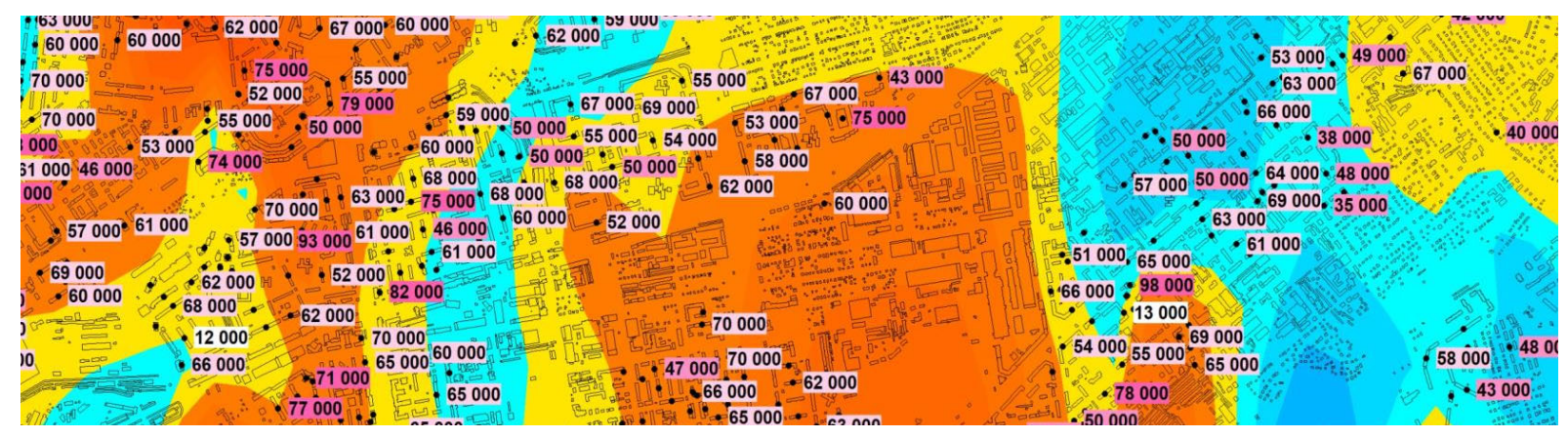

Рис. 3. Буквенно-цифровой способ картографической визуализации значений стоимости объектов недвижимости 
- комбинированное разномасштабное представление картографической информации по ценовому зонированию территории. Данный способ является более трудозатратным, так как предполагает создание нескольких карт различного масштаба - обзорной карты мелкого или среднего масштаба и детальной карты крупного масштаба. Пример реализации данного способа построения геокогнитивной карты показан на рис. 4. На обзорную карту территории города Новосибирска в масштабе $1: 10000$ нанесены номера микрорайонов или кварталов городской застройки с однородными по стоимости объектами недвижимости. На планах более крупного масштаба показано детальное расположение зданий и объектов инфраструктуры внутри оцениваемого микрорайона, а также дана информация о принадлежности объектов недвижимости к определенной стоимостной зоне;

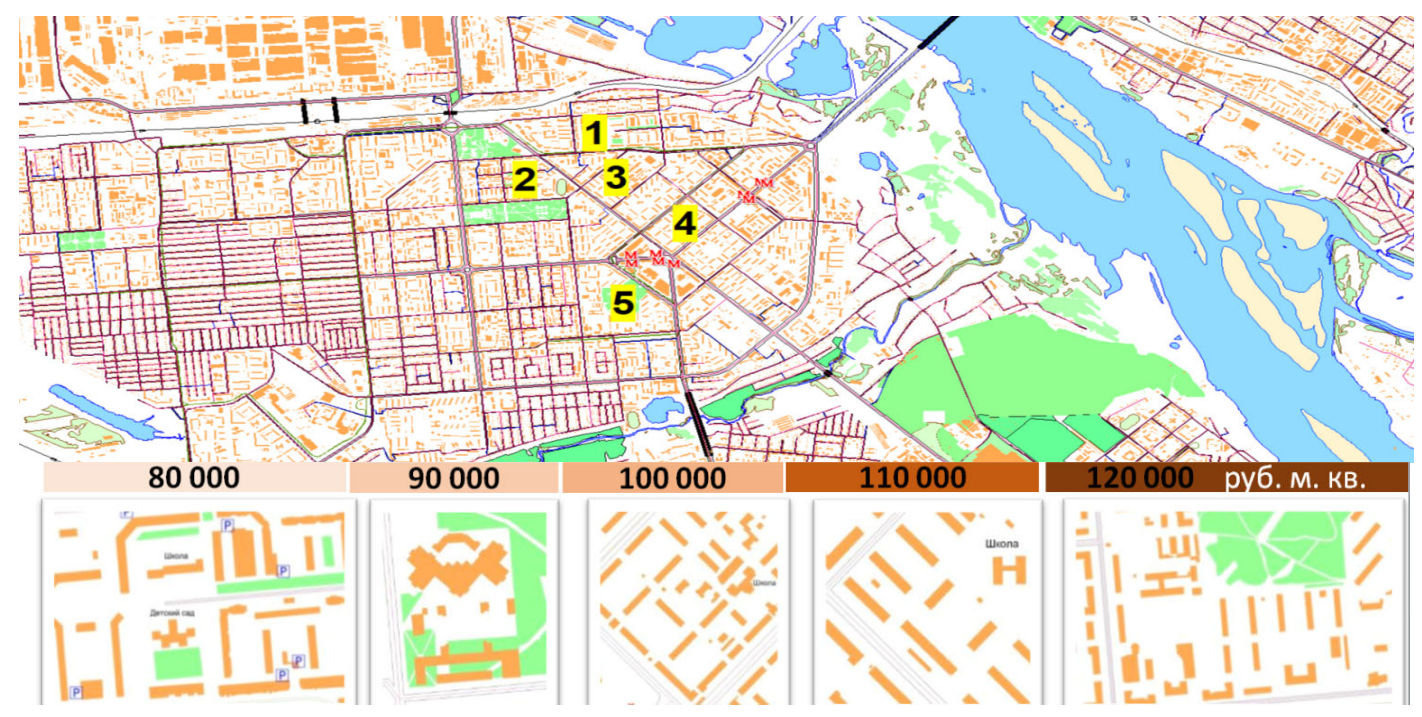

Рис. 4. Комбинированное разномасштабное представление картографической информации по ценовому зонированию территории

- применение геометрических фигур (как правило, окружностей или прямоугольников), отражающих зону локализации картографируемого параметра. Данный способ прост и удобен, так как позволяет на карте мелкого масштаба наглядно отразить ценовые зоны, а также их стоимостные характеристики, рис. 5;
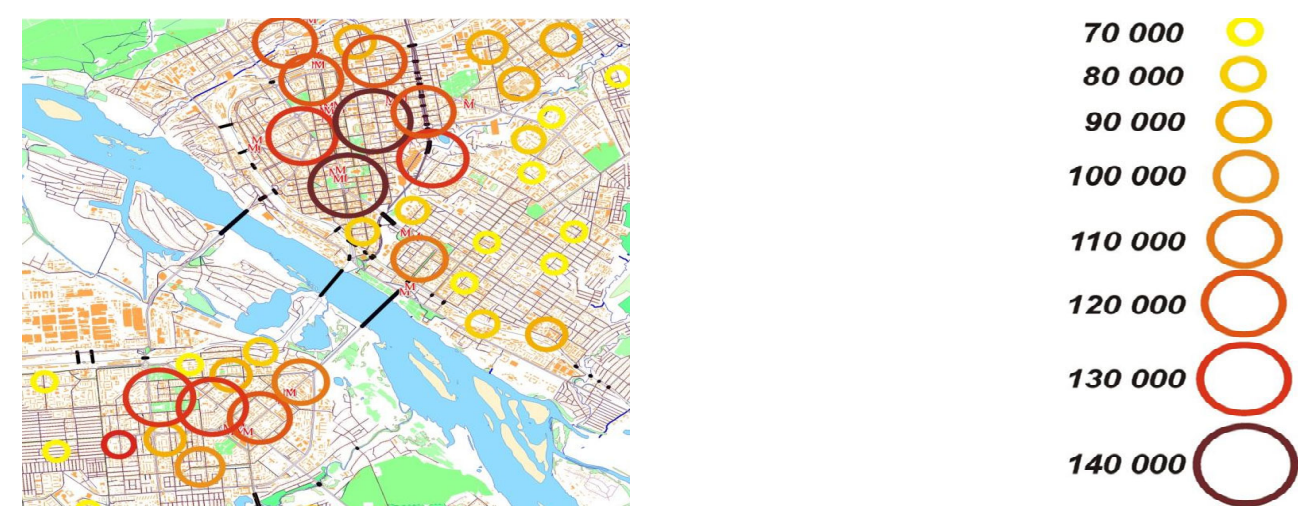

Рис. 5. Пример применения способа геометрических фигур для создания когнитивной карты ценового зонирования 
- применение рейтинговой системы для отображения картографируемого параметра. При этом способе необходимо выполнить первоначальное зонирование территории и присвоение номера в рейтинге оцениваемых микрорайонов или кварталов, рис. 6. Как и в предыдущем способе в качестве подложки используется карта мелкого масштаба с нанесенными номерами микрорайонов, соответствующих определенному значению в рейтинге по стоимости объектов недвижимости;
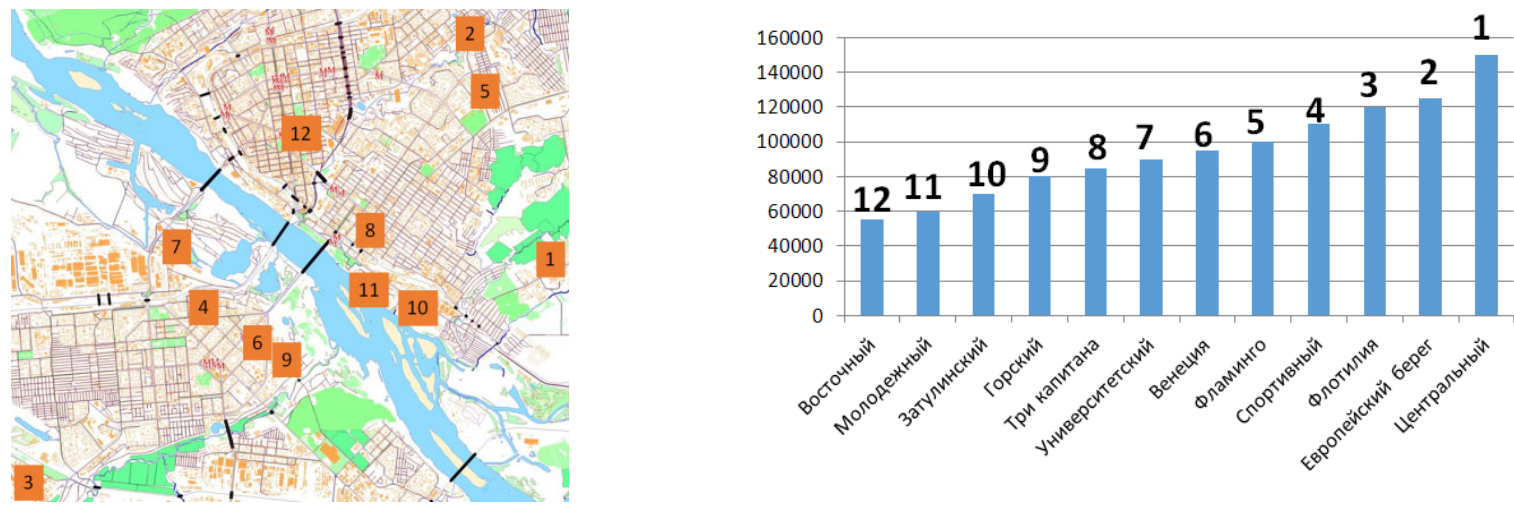

Рис. 6. Рейтинговая система для отображения стоимости объектов недвижимости в микрорайоне города

- одним из перспективных способов создания геокогнитивных карт является трехмерная визуализация данных о ценовом зонировании [13]. Особенно важным является выполнение вертикального ценового зонирования объектов недвижимости, так как в зависимости от этажности зданий может изменяться ценовая категория объектов недвижимости, которые в нем расположены;

- несомненно, будущее кадастра, цифровой картографии, геоинформатики и территориального управления неразрывно связано с задачами, возникающими при управлении объектами недвижимости. Для принятия оперативных, оптимальных управленческих решений даже при наличии нормативно-правовых регламентов и автоматизированных систем поддержки принятия решений, важная роль отводится экспертному анализу. При наличии геокогнитивного картографического представления предметной области эксперт сможет верно оценить ситуацию и рекомендовать оптимальную последовательность действий для целей обеспечения устойчивого развития территории.

\section{БИБЛИОГРАФИЧЕСКИЙ СПИСОК}

1. Анализ ценообразующих факторов, оказывающих влияние на кадастровую стоимость недвижимости / А. В. Дубровский, А. Л. Ильиных, О. И. Малыгина, В. Н. Москвин, А. В. Вишнякова // Вестник СГУГиТ. - 2019. - Т. 24, № 2. - С.150-169.

2. Подрядчикова Е. Д. Усовершенствование методики земельно-оценочных работ на основе геоинформационного анализа социально-территориальных взаимосвязей элементов городской инфраструктуры // Изв. вузов. Геодезия и аэрофотосъемка. -2015 . - № 5/С. C. 230-234. 
3. Подрядчикова Е. Д., Гилёва Л. Н., Дубровский А. В. Корреляционно-регрессионный анализ кадастровой стоимости объектов недвижимости и ценообразующих факторов (на примере земельных участков города Тюмени, предназначенных для индивидуальной жилой застройки) // Вестник СГУГиТ. - 2020. - № 1 (25) - С. 274-286.

4. Генеральный план развития города Новосибирска [Электронный ресурс] / Департамент строительства и архитектуры мэрии города Новосибирска - Режим доступа: http://dsa.novo-sibirsk.ru/ru/site/1311.html - Загл. с экрана.

5. Грахова, Е.В. Анализ ценообразующих факторов на рынке жилой недвижимости в 2018 году [Текст] / Е.В. Грахова, Д.А. Агафонова, Д.В. Наольских - Вестник Челябинского Государственного Университета №12(422) - 2018 - С. 124 -131.

6. Дубровский, А. В. Совершенствование методической основы государственной кадастровой оценки объектов жилого фонда [Текст] / А. В. Дубровский, В. А. Махт, Е. А. Козочкина // - Вестник СГУГиТ, № 4 - 2017. - с. 25 - 35.

7. Иоселиани, Н. А. Методические подходы к оценочному зонированию для целей государственной кадастровой оценки [Текст] / Н. А. Иоселиани - Имущественные отношения в Российской Федерации, № 7 - 2018. - С. 41-49.

8. Василенко, Т. О. Генри и когнитивные карты [Электронный ресурс] - Режим доступа: http://www.improvement.ru/zametki/cognitive/.

9. Янкелевич, С. С. Концепция нового вида карт, основанного на знаниях [Текст] / С. С. Янкелевич, Е. С. Антонов // Вестник СГУГиТ. - 2019. - Т. 24, № 4. - С. 188-196.

10. Антонов, Е.С. Геокогнитивные карты и технологии - новый этап в картографии [Текст] / Е.С. Антонов // Вестник СГУГиТ. -2020. - Т. 26, № 2. - С. 140 - 150.

11. Дубровский, А.В. Классификация способов картографической визуализации показателей социальной комфортности территории населенного пункта [Текст] / А.В. Дубровский, Е.Д. Подрядчикова - Известия вузов. Геодезия и аэрофотосъемка. - 2015. -№ 5/С. - С. 225228.

12. Беляева А. В. Использование пространственных моделей в массовой оценке стоимости объектов недвижимости. // Компьютерные исследования и моделирование. - 2012 - Т. 4, № 3 - С. 639-650.

13. Трехмерная визуализация неблагоприятных природных условий для корректировки кадастровой стоимости земель / Е. И. Аврунев, Н. В. Гатина, М. В. Козина, В. К. Попов // Известия Томского политехнического университета. Инжиниринг георесурсов. - 2019. - Т. 330, № 1. - C. 181-190.

(C) Е. С. Антонов, А. В. Дубровский, Н. А. Беляева, 2021 